\title{
A Heat Control Mechanism on the Extruder System of the Chocolate 3D Printer Machine
}

\author{
Setyawan Wibowo ${ }^{1 *}$, Mokhammad Samsudin ${ }^{1}$, Soeadgihardo Siswantoro ${ }^{1}$, \\ Muhammad Musthofa ${ }^{1}$, Reza Mahardika ${ }^{1}$, Rafiq Aly Nurdin ${ }^{1}$
}

\author{
${ }^{1}$ Mechanical Engineering Vocational College Universitas Gadjah Mada Yacaranda Street, Sekip Unit IV \\ Yogyakarta , Indonesia \\ *Corresponding author.Email: setyawanbw@ugm.ac.id
}

\begin{abstract}
The use of digital fabrication for the field of food processing has been widely used both for process efficiency, improving food quality, product innovation, and special needs. The use of 3D printers to print food is a challenge for the food industry in the future, one of which is the chocolate industry. In the chocolate 3D Printer machine, an essential process is the heating mechanism of the extruder. Proper heating will allow the chocolate to melt well and easily push out of the extruder to print. This study used an AC heater to heat the extruder and was combined with a fan towards the extruder to maintain temperature stability. The use of heating devices and cooling fans has been set to maintain the chocolate's minimum and maximum heat set-points to maintain the allowable temperature. The result of the research was a configuration of heating and cooling settings on the extruder $3 \mathrm{D}$ printer so that the heating process was stable at the allowable temperature. The best melting conditions have occurred at a temperature setting between $31-32.5^{\circ} \mathrm{C}$, resulting in an actual chocolate temperature between $33^{\circ}-47^{\circ} \mathrm{C}$.
\end{abstract}

\section{Keywords: 3D Printer, Heat Control, Extruder System, Food Processing}

\section{INTRODUCTION}

The development of digital fabrication is currently very fast. Digital fabrication is a type of manufacturing process where the machines used are controlled by a computer. It is classified according to processes that work on the physical and/or chemical properties of the materials used, such as additive procedures, subtractive procedures, and formative procedures [1], and the joining method [2]. In addition, digital fabrication is also known as rapid prototyping, which is a type of manufacturing process using a machine controlled by a computer, including 3D printer technology and cutting machines (laser cutters and $\mathrm{CNC}$ ). The equipment in the most extensive and varied use of digital manufacturing is the 3D printer. So that digital fabrication, often referred to as 3D printer technology, will create physical objects from representative models that have been previously designed [3]. The use of 3D printer technology in such a way as to represent object models in 3 dimensions has made this technology evolve for various needs, especially prototyping technology.
The advantages of 3D printers for food needs in addition to unlimited freedom and ideas from packaging and creativity in food forms include: (1) solving the problem of food scarcity, (2) eliminating malnutrition, (3) reducing climate change due to changing food production patterns, (4) changes in food business patterns, and (5) solving problems of supplying food for special needs such as trips to astronauts and military personnel [4]. These advantages and changes will impact the development of advanced technology and the pattern of people's lives which are widely discussed as the disruptive era.

There are two main reasons for customizing food for each consumer, namely health and preferences. Many people have problems digesting food. Moreover, each disease and condition requires dietary adjustments as part of treatment and management $[5,6]$. The customization nature of the $3 \mathrm{~d}$ printer allows nutrition and food types to be adjusted for patient edited needs. In addition, some patients have difficulty chewing on standard forms of food in certain conditions, so it is necessary to adjust the shape with a $3 \mathrm{~d}$ printer to allow the shape according to the needs of each person so that it is easy to chew [7]. 
The emergence of creative industries and various food businesses nowadays also raises creative ideas in the presentation of various foods. Various types of food began to be made with various customization techniques using layer manufacturing techniques [8-10]. Various materials such as foods derived from sugar, sweets, vegetables, cakes, and chocolate are widely varied for creative food businesses. The existence of a $3 \mathrm{~d}$ printer technique will support the creation of offerings, and the kinds of creative food ideas are growing more rapidly $[10,11]$.

Some of these research considerations can inform that certain needs in food are quite important, including the manufacture of chocolate food innovations. To be able to produce a good form of chocolate food, of course, it requires conditioning so that the chocolate, when melted, remains in good condition and supports the formation process. Therefore the heating technique will be very important for the successful formation of chocolate food. Several existing studies $[12,13]$ show that heat is good for chocolate management at a temperature of $40^{\circ} \mathrm{C}$. This research will examine the configuration of heating equipment settings on the chocolate $3 \mathrm{~d}$ printer extruder to get good chocolate printing results.

\section{METHODS}

Before being processed by a $3 \mathrm{~d}$ printer, the chocolate needs to be melted first. During the melting process, special treatment was needed so that during the pressing process, the chocolate can come out and melt in accordance with good printing conditions. Different types of chocolate also have different treatments. The melting process is carried out in a chamber connected to a nozzle to remove the chocolate coating. Chocolate needs to be kept at a temperature so that it stays in a melted state. Setting the minimum temperature set-point and maximum temperature on the thermometer control is very important in order to maintain the temperature of the chocolate according to the melting temperature.

The heater must be in a good position to stay even and not burn the chocolate. The temperature setting, which is too high, will cause the chocolate to spoil, or if the melting temperature is too high, the chocolate will be too liquid and difficult to form. On the other hand, if the temperature is low, the chocolate will not melt or can not be pressed to get out of the nozzle. The melting temperature was set between $35-45^{\circ} \mathrm{C}$ in order to obtain good printing conditions. Nozzle construction should be made so that the melted chocolate can be pressed directly into the nozzle tip to shape according to the design. The tip of the nozzle is made conical with a diameter of $4 \mathrm{~mm}$.

Another process that needs to be considered is the cooling process. The cooling process will cause the chocolate liquid that is formed to harden and form objects according to the product design. The cooling process is carried out on the chocolate material after it comes out of the nozzle tip and forms a layer of the object. Fan and wind speed settings were needed so that the cooling process did not damage the printout. The extruder heating process uses a $220 \mathrm{~V}, 150$-watt heater with a Thermo control setting as shown in Figure 1.a

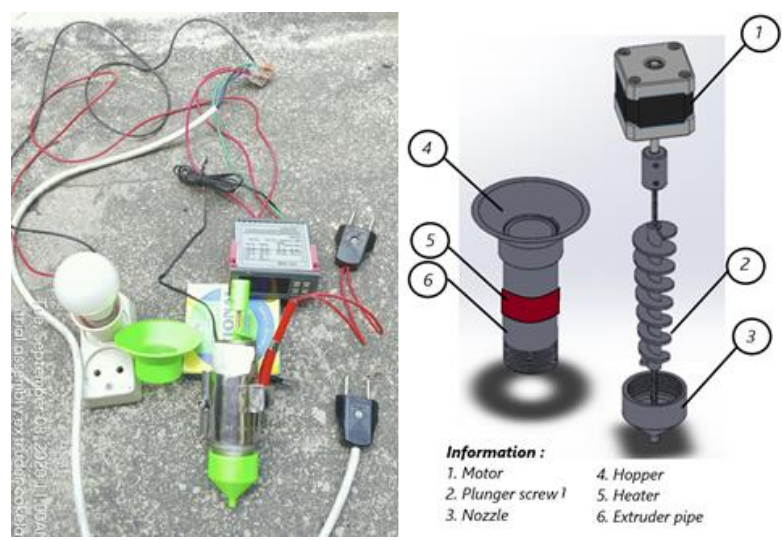

Figure 1 Schematic of the equipment and installation of the heater in the extruder.

The testing process is carried out by adjusting the minimum and maximum heating temperature settings using a temperature control so that the temperature range is at the specified operating temperature. Another test is to adjust the heating section of the extruder pipe at the lower (low), middle (middle), and top (top) height levels, as shown in figure $1 \mathrm{~b}$. This arrangement is made to determine the temperature distribution of the chocolate throughout the inside of the extruder. The configuration of the heating process in the extruder will be determined from the testing process, especially for the minimum and maximum temperature settings on the thermometer control.

\section{RESULTS AND DISCUSSION}

The characteristics of the mechanical properties of the edible films produced were analyzed through tensile strength and elongation at break tests. The mechanical properties of edible films are shown in Figure 2 dan 3. These figures show that the addition of CNC improved the mechanical properties of edible films. The addition of $\mathrm{CNC}(2.5 \% \mathrm{w} / \mathrm{w})$ produced the highest tensile strength, it was $5.72 \%$. The same results were also informed by [17][28][29]. Tensile strength increased (4.09 to 8.76 $\mathrm{MPa}$ ) with increase in cellulose nanofibers (CNF) concentration from $0 \%$ to $36 \%$ [17]. [28] proposed nanocomposites using chitosan (CS) as nanofiller in HPMC to 
improve mechanical and film barrier properties. Different concentrations of CS nanoparticles were incorporated in HPMC to evaluate changes in mechanical properties, water vapor permeability (WVP), and oxygen permeability. Incorporation of chitosan nanoparticles in the films improved tensile strength (30.7 to $66.9 \mathrm{MPa})$ and film barrier properties. [29] reported tensile strength increased by $56 \%$, for films reinforced with CNC from garlic stalks, reinforcement was found to be optimum at a starch to CNC ratio of 100:5. Increased tensile strength caused by CNC as a filler that fills the PLA matrix and the presence of CNC and PLA interface adhesion forces. Interface adhesion from PLA and CNC is caused by both containing hydroxyl groups that form hydrogen bonds interfaces. The strong hydrogen bonding

between the CNC and PLA faces causes effective reinforcement of the matrix. However, increasing the number of CNCs can cause damage to mechanical properties. As the number of $\mathrm{CNC}$ increases, elongation at break also increases. The highest elongation at break is $22.4 \%$ at the addition of $20 \%$ CNC.

The increase of elongation at break from PLA-CNC blend film was caused by CNC which fills the PLA matrix and the presence of plasticizers in the form of polyethylene glycol by $10 \%$ (W) of PLA and CNC total weight. From the research results on the heating mechanism in the extruder system, it was found that the heating process using a 150 watt $\mathrm{AC}$ heater was fast enough to increase the temperature. The process of setting the minimum and maximum temperature values must be careful enough so that the actual chocolate temperature result can be as expected. The test results of the temperature limit setting are presented in Table 1.

From table 1, it is shown that setting the temperature control greatly affects the actual condition of the chocolate temperature. The control system used using the on-off control has not been able to make the chocolate temperature range at the planned temperature. The temperature overshoot produced by the heater after reaching the maximum temperature and the system is turned off still produces heat that reaches more than $50{ }^{\circ} \mathrm{C}$. Therefore, it is necessary to add a cooling fan in order to reduce the effect of temperature overshoot and condition the chocolate temperature according to the planned temperature.

In the experiment, two tests of minimum and maximum temperature settings were carried out at the control temperature, namely in the first experiment was 31.5 $32^{\circ} \mathrm{C}$ and the second was $32.5-32^{\circ} \mathrm{C}$. The use of the AC 150 heater was quite responsive in heating so that the temperature setting is in a low range. The results obtained as shown in figure 2, namely the first test, showed that the resulting chocolate temperature range was between $33.3-43.5^{\circ} \mathrm{C}$. While the chocolate that has been stirred, the maximum temperature reaches $46.8^{\circ} \mathrm{C}$. Meanwhile, the second test showed that the mixed chocolate temperature was close to $50^{\circ} \mathrm{C}$, and some were even higher. So the recommended temperature setting is in the first test configuration. The time it takes to steady indicates a decline and towards convergence. This shows that the heating stability of the extruder system can take place continuously.

Table 1. Temperature measurement results from the minimum and maximum value settings.

\begin{tabular}{|c|c|c|c|c|c|c|c|c|}
\hline \multirow{2}{*}{$\begin{array}{l}\text { Test } \\
\text { No. }\end{array}$} & \multicolumn{3}{|c|}{ Temperature control } & \multicolumn{4}{|c|}{ Chocolate temperature (Actual) } & \multirow{2}{*}{$\begin{array}{l}\text { Cooling } \\
\text { Type } \\
\text { and } \\
\text { position }\end{array}$} \\
\hline & $\operatorname{Tmin}\left({ }^{0} \mathrm{C}\right)$ & $\operatorname{Tmax}\left({ }^{\circ} \mathrm{C}\right)$ & time (s) & $\operatorname{Tmin}\left({ }^{\circ} \mathrm{C}\right)$ & $\operatorname{Tmax}\left({ }^{\circ} \mathrm{C}\right)$ & $\begin{array}{l}\text { Tmax }\left({ }^{\circ} \mathrm{C}\right) \\
\text { after mix }\end{array}$ & time (s) & \\
\hline A1 & 31.5 & 32 & 15 & 33.3 & 43 & 46.8 & 120 & \multirow{6}{*}{$\begin{array}{c}\text { Fan } 12 \mathrm{~V} \\
\text { within } \pm \\
5 \mathrm{~cm} \\
\text { from the } \\
\text { heater }\end{array}$} \\
\hline $\mathrm{A} 2$ & 31.5 & 32 & 15 & 33.3 & 43 & 46.6 & 100 & \\
\hline A3 & 31.5 & 32 & 15 & 33.3 & 43 & 46.7 & 80 & \\
\hline A4 & 31.5 & 32 & 14 & 33.3 & 43.5 & 46.6 & 80 & \\
\hline A5 & 31.5 & 32 & 10 & 33.3 & 39 & 46.7 & 85 & \\
\hline A6 & 31.5 & 32 & 10 & 33.3 & 41 & 46.7 & 85 & \\
\hline B1 & 32.5 & 33 & 12 & 34.6 & 45 & 48.2 & 120 & \multirow{6}{*}{$\begin{array}{c}\text { Fan } 12 \mathrm{~V} \\
\text { within } \pm \\
5 \mathrm{~cm} \\
\text { from the } \\
\text { heater }\end{array}$} \\
\hline B2 & 32.5 & 33 & 13 & 34.7 & 45 & 48.5 & 120 & \\
\hline B3 & 32.5 & 33 & 13 & 34.7 & 45 & 49 & 110 & \\
\hline B4 & 32.5 & 33 & 13 & 34.6 & 46 & 48.6 & 110 & \\
\hline B5 & 32.5 & 33 & 13 & 35.6 & 46 & 53.5 & 90 & \\
\hline B6 & 32.5 & 33 & 12 & 34.5 & 46 & 48.5 & 80 & \\
\hline
\end{tabular}



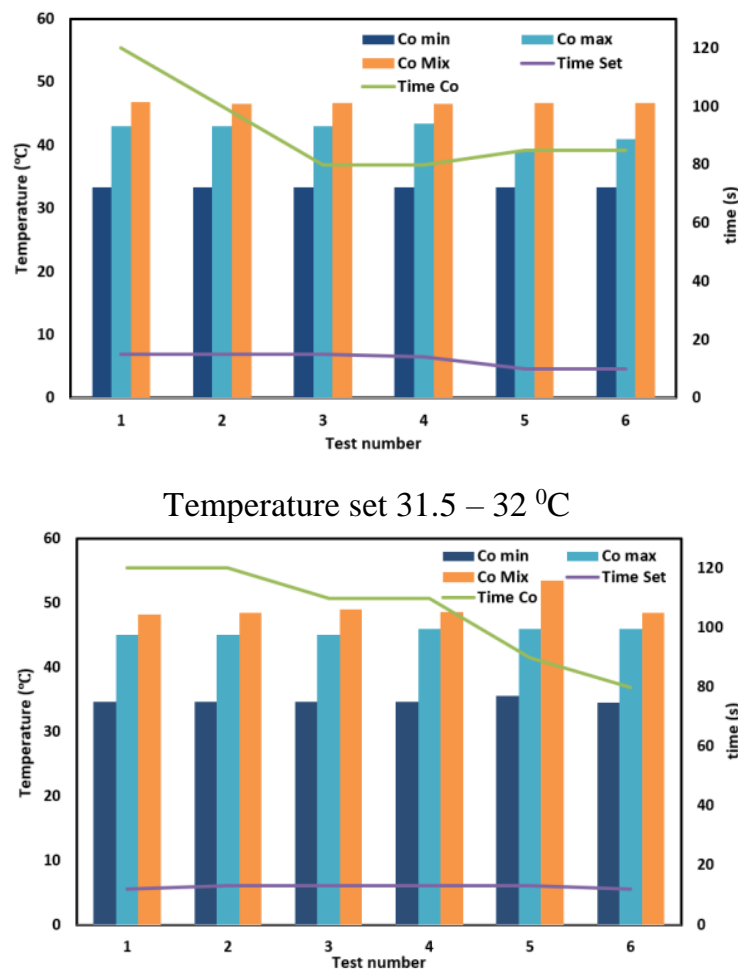

Temperature set $32.5-33{ }^{\circ} \mathrm{C}$

Figure 2. Temperature distribution and time reach for each set temperature.

The operational temperature is the tempera-ture that is planned during the chocolate molding process. Changes in temperature cause changes in the characteristics, shape, and thickness of the chocolate to be processed. Testing of changes in temperature and its effect on the shape of the chocolate is visually shown in Figure 3. From this figure, it can be seen that the character of the chocolate melts at a temperature of $33-60{ }^{\circ} \mathrm{C}$.
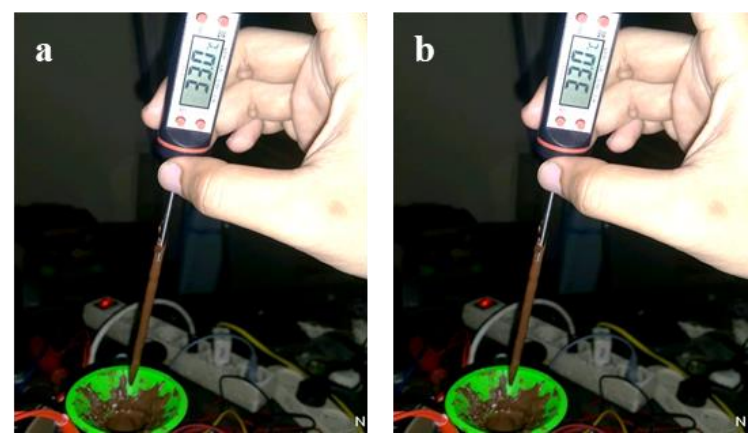
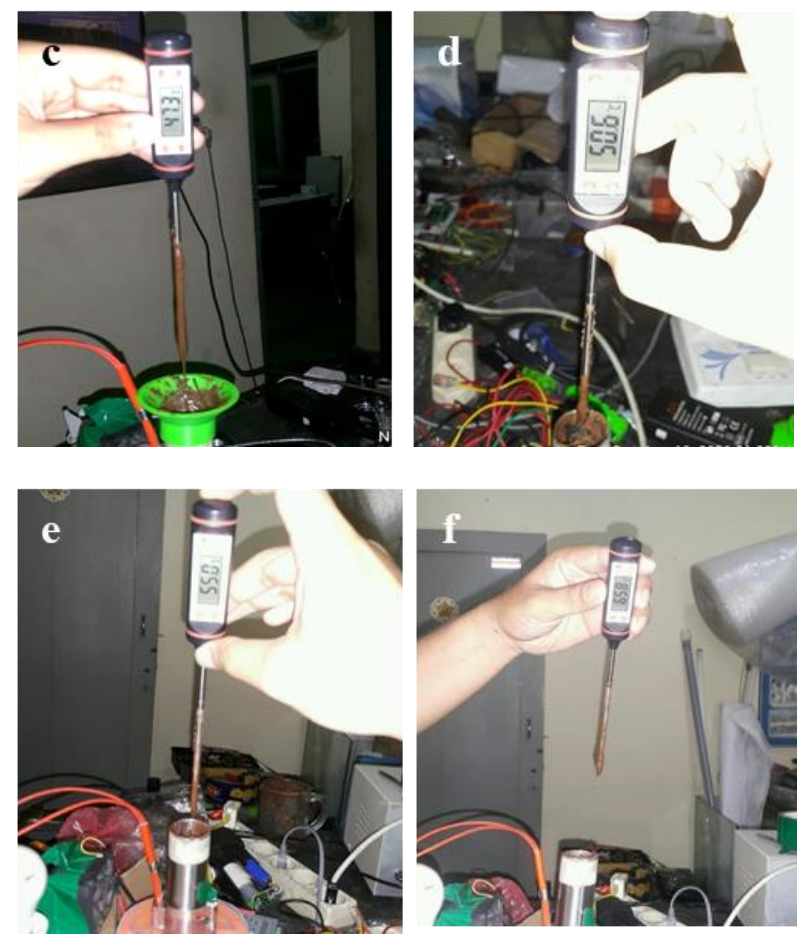

Figure 3. Visual appearance of chocolate viscosity with temperature variations; $\mathrm{T}=33{ }^{\circ} \mathrm{C}(\mathrm{a}) ; \mathrm{T}=38.2{ }^{\circ} \mathrm{C}(\mathrm{b}) ; \mathrm{T}$ $=47.3{ }^{\circ} \mathrm{C}(\mathrm{c}) ; \mathrm{T}=50.6{ }^{\circ} \mathrm{C}(\mathrm{d}) ; \mathrm{T}=55^{\circ} \mathrm{C}(\mathrm{e}) ; \mathrm{T}=65.8{ }^{\circ} \mathrm{C}$ (f).

The test results show that when the chocolate tem-perature starts from $33{ }^{\circ} \mathrm{C}$, it has melted the higher the temperature, the viscosity of the chocolate de-creases, meaning that the chocolate is thinner than before. At temperatures above $50{ }^{\circ} \mathrm{C}$, chocolate tends to thicken and begin to be difficult to form. The na-ture of chocolate that is too dense or too thin is also not good in the forming process for $3 \mathrm{D}$ printers. Therefore, the ideal chocolate condition for the form-ing process was chosen. The test results show that when the chocolate temperature is between 33 ${ }^{\circ} \mathrm{C}$ to $47^{\circ} \mathrm{C}$, it is a condition that allows the chocolate to form properly.

The research results found that to get the ideal temperature range for the forming process, namely, at a chocolate temperature between $33-47^{\circ} \mathrm{C}$, set-point temperature control is needed at Tmin $31.5^{\circ} \mathrm{C}$ and $\mathrm{Tmax} 32.5^{\circ} \mathrm{C}$.

\section{CONCLUSION}

From the results of the study, it can be concluded that the process of printing chocolate on a $3 \mathrm{~d}$ printer machine requires the following heating settings:

1. The melting temperature for the $3 \mathrm{D}$ printer is in the temperature range of $33-47^{\circ} \mathrm{C}$. 
2. The temperature control settings are configured with a lower temperature limit of $31.5{ }^{\circ} \mathrm{C}$ and an upper limit of $32{ }^{\circ} \mathrm{C}$ to obtain a chocolate temperature condition with a range of $33-47^{\circ} \mathrm{C}$.

\section{ACKNOWLEDGMENT}

The author would like to express heartfelt gratitude to Universitas Gadjah Mada and Vocational College UGM for their assistance in funding and facilities. We appreciate the help of the eSVe Fablab Team for useful sessions, helpful suggestions, and collaboration, which we gratefully acknowledged.

\section{REFERENCES}

[1] Chua C K, Leong K F and Lim C S 2003 Rapid Prototyping: Principles and Applications 2nd Edition (World Scientific Publishing Company)

[2] Addington D M and Schodek D L 2005 Smart Materials and New Technologies: For the Architecture and Design Professions (Architectural Press)

[3] Shahrubudin N, Lee T C and Ramlan R 2019 An overview on 3D printing technology: Technological, materials, and applications Procedia Manufacturing 35 1286-96

[4] Tran J L 2016 3D-Printed Food The Minnesota J. of Law, Sci. Technol 17 857-79

[5] Lipton J I 2017 Printable food: the technology and its application in human health Curr Opin Biotechnol 44 198-201

[6] Singh P and Raghav A 2018 3D Food Printing: A Revolution in Food Technology Acta Scientific Nutritional Health 2 11-2

[7] Hemsley B, Palmer S, Kouzani A, Adams S and Balandin S 2019 Review Informing the Design of 3D Food Printing for People with Swallowing Disorders: Constructive, Conceptual, and Empirical Problems Proc. of the 52nd Hawaii Int.Conf. on System Sciences (University of Hawai'i at Manoa) pp 5735-44

[8] Wegrzyn T F, Golding M and Archer R H 2012 Food Layered Manufacture: A new process for constructing solid foods Trends in Food Science and Technology 27 66-72

[9] Severini C, Derossi A and Azzollini D 2016 Variables affecting the printability of foods: Preliminary tests on cereal-based products Innovative Food Science and Emerging Technologies 38 281-91

[10] Sun J, Peng Z, Zhou W, Fuh J Y H, Hong G S and Chiu A 2015 A Review on 3D Printing for Customized Food Fabrication Procedia Manufacturing 1 308-19
[11] Izdebska J and Zołek-Tryznowska Z 2016 3D food printing - Facts and future Agro Food Industry HiTech 27 33-7

[12] Siti Ramlah 2016 Quality and Taste Characteristics of Polyphenol Rich Chocolate Jurnal Industri Hasil Perkebunan 11 23-31[in Indonesia]

[13] Indarti E, Arpi N and Budijanto S 2013 Study of Chocolate Bar Making by Tempering and Untempering Methods Jurnal Teknologi dan Industri Pertanian Indonesia 5 1-6 [in Indonesia] 